\title{
Effect of Structure of Internal Waves on Energy Transfer and Flow Control Between South and Middle Basins of Caspian Sea
}

\author{
Ashrafoalsadat Shekarbaghani ${ }^{1}$ \\ ${ }^{1}$ Organization for Educational Research and planning(OERP), Iran \\ Correspondence: Ashrafoalsadat Shekarbaghani, Assistant Professor in Physics Department of Science \& \\ Mathematics Education, of Education Studies Research Center, Organization for Educational Research and \\ planning(OERP), Iran, Tehran. E-mail: a20.baghani@gmail.com
}

Received: December 10, 2015

Accepted: January 10, 2016

Online Published: January 13, 2016

doi:10.5539/mas.v10n3p33

URL: http://dx.doi.org/10.5539/mas.v10n3p33

\begin{abstract}
In this study, role of internal waves in controlling stratified exchange flows between south and middle basins of Caspian Sea and energy transfer have been studied. The studies have been conducted based on field and theoretical studies based on numerical calculations. In this investigation, Caspian Sea has been considered as stratified and Boussinesq approximation has been considered. In equations governing the movement, cohesion and compressibility have been neglected. In the field studies, investigation of density profiles indicate signs of stratified structure which so far has been attributed to dual distribution convection phenomenon, but by considering density ratio profile and values of density ratio which are mostly negative numbers, the factor causing stratified structure of Caspian Sea can be attributed to existence of internal waves. Density field in these two basins indicate that the middle basin has higher average density compared to the south basin, this fact can cause creation of a gravity exchange flow. This exchange flow causes creation of internal waves in this sea that can have a modal structure towards vertical direction. In theoretical studies, the two middle and south basins of Caspian Sea are networked in two dimension X-Z systems and equations governing movement are solved through a numerical method by using finite difference method and the vertical velocity values obtained in 290 points of the network was almost $10^{-6}$ to $10^{-4} \mathrm{~m} / \mathrm{s}$, meaning that vertical movements are much smaller. Values obtained for horizontal velocity are almost $10^{-3}$ to $10^{-1} \mathrm{~m} / \mathrm{s}$. Vertical and horizontal velocity profiles obtained from solution of these equations and also density profile obtained in four integration periods indicate that as a result of passage of gravity flow between the two basins, density in various points of the two basins change. The structure created from internal waves on the crest causes creation of shear strata observed. This structure can be effective in exchange of the two basins. Therefore, in transfer and energy conversion, identification of the created strata is of a high importance.
\end{abstract}

Keywords: internal waves, normal modes, distribution convection, gravity flow, Caspian Sea

\section{Introduction}

Observations indicate existence of stratified structure in seas; so that the way of creation of stratified structure has always been a question. Different mechanisms such as dual distribution, internal waves, and turbulent mixing have been proposed for creation of them [2]. Ruddick [1992] believes that existence of stratified structure depends on dual distribution [3], but in the Caspian Sea the conditions of creation of dual distribution are less observed. Hence, existence of internal waves should cause creation of stratified structure. Therefore, mechanisms of internal waves are more acceptable for creation of a stratified structure. Existence of internal waves in stratified environments such as sea is very common. These waves have a more effective role in transferring the momentum in sea $[4,5]$.

Normal modes of these waves cause creation of shear layers which have also been observed in experimental mediums [6]. The stratified structure related to normal modes of these waves can be important in vertical and horizontal transfer in marine environments or diffusion of sound waves which are usually used for searching in seas.

Wong et al. (2001) indicated that in closed environments, flows due to plumes that move in the bottom of the closed basin have caused internal waves that their phase velocity is towards down and their group velocity is towards up directions. Equality of their phase velocity with advection velocity due to plume with filling box 
mechanism, cause creation of semi-stationary modal structure. Also this structure has caused creation of shear strata (5 to 7$)$ which are effective in creation of stratified structure of physical quantities such as salinity and temperature [6].

Vertical structure of physical properties such as salinity and temperature in lakes also indicate these strata. For instance, Boehrer (2000) by investigating vertical structure of salinity and temperature in Constance Lake indicated that regular strata are observed in them so that internal waves can be analyzed into modes that each can transfer independently, considering this fact that independent waves in lakes can be observed with higher probability. Therefore, the hypothesis that in lakes, all water motions end in internal waves is a reasonable hypothesis. Hence, he attributed the profile of flow velocity in Constance Lake to the velocity obtained from solving equations of internal waves and by proposing an analytic model of normal modes of internal waves, justified them [7].

Hogg et al. (2000) investigated role of internal waves in controlling stratified exchange flows between two closed marine basins by solving equations governing movement with numerical methods by determining Eigen value matrix. At first, created internal waves in an experimental simulation in order to create exchange flow in a reservoir including the two basins, then by examining waves in terms of location and time, calculated propagation velocity. After this operation, based on theory of hydraulic control in stratified current conservation, fluid velocity in defined and separate strata that their interaction occurs only in limited conditions was calculated and then compared with velocity of internal waves in the water column [8].

Bains and Turner (1969) indicated that gravity flows cause modal movements (together with internal waves) [9]. Hydrographical structure of Caspian Sea which is a closed lake is in such a way that can be considered in two middle and south basins. Existence of a mound between middle and south basins of Caspian Sea which is almost located beside Abshouran peninsula, causes that flow exchange between the two basins from top of the mound, cause creation of internal waves. Meaning that the gravity flow between the two basins especially on the bottom towards the south basin from top of the mound in the stratified area, causes creation of such waves. On the other hand, modal structure of these waves should be effective in the way of flow exchange between these two basins.

In this research an analytic (numerical) model has been proposed and compared with field observations and the obtained results are discussed. These results can be compared with those obtained from studies conducted by Boehrer and Hogg et al., and it is found that there is an appropriate consistency between these results.

Several studies have been conducted on coastal areas and waves caused by winds in the Caspian Sea, however, few studies have been conducted on marine physics of various parts of Caspian Sea. Therefore, it seems that the present study is a new approach in terms of issues of marine physics related to internal parts of the Caspian Sea especially in Abshouran region.

\section{Field Study}

In this research, the obtained data by CTD measurements have been used for providing $\sigma_{t}$ profile. Plan of the Caspian Sea and CTD measurement stations have been indicated in the first research tour of the International Atomic Energy Agency in figure 1 [1]. Field observations indicate $\sigma_{t}$ profile of stratified structure of the Caspian Sea in figure 3. $\sigma_{\mathrm{t}}$ values in these waters are often negative and less than one.

\section{Analytic Model}

Internal waves in an area with density stratification can be obtained by analysis of the movement equations. In small movements, amplitude of pressure and density changes are as follows, respectively:

Where,

$$
\begin{aligned}
& P=P(z)+P^{\prime}(x, y, z, t) \\
& \rho=\rho(z)+\rho^{\prime}(x, y, z, t)
\end{aligned}
$$

$\mathrm{P}(\mathrm{Z})$ is hydrostatic distribution of pressure in water column and $\mathrm{P}^{\prime}$ represents fluctuations of pressure, $\rho(z)$ is vertical distribution of density field and $\rho^{\prime}$ is also changes related to density field. Horizontal components of fluid's movement are as follows:

$$
\begin{aligned}
& \rho(u t-f v)=-P^{\prime} x \\
& \rho(v t-f u)=-P^{\prime} y
\end{aligned}
$$

And its vertical component is:

$$
\rho(w t)=-P_{z}^{\prime}-g \rho^{\prime}
$$


And the indexes are indicating the partial derivative (for example $U t=\frac{\partial u}{\partial t}$ ). Also $f=2 \Omega \sin \Phi$ is the Coriolis parameter so that $\phi$ is the latitude and $\Omega$ is the angular velocity of the ground. Mass continuity equation for incompressible conditions is also as follows:

$$
\mathrm{u}_{\mathrm{x}}+\mathrm{v}_{\mathrm{y}}+\mathrm{w}_{\mathrm{z}}=0
$$

Also buoyancy conservation equation is:

$$
0=\frac{d \rho}{d z}{ }_{t}+w \rho^{\prime}
$$

The equation indicates local changes of density due to vertical movements of the fluid in density field with vertical gradient. By combining these equations an equation based on vertical component of the velocity of fluid movement can be obtained [10]:

$$
\frac{\partial^{2}}{\partial t^{2}} \nabla^{2} w+N^{2} \nabla_{H}^{2} w+f^{2} \frac{\partial^{2} w}{\partial z^{2}}=0
$$

Where $\mathrm{N}$ is frequency of buoyancy of the environment and is:

$$
\begin{gathered}
N^{2}=\frac{g}{\rho} \frac{\partial \rho}{\partial z}, \\
\nabla_{H}^{2}=\frac{\partial^{2}}{\partial x^{2}}+\frac{\partial^{2}}{\partial y^{2}}
\end{gathered}
$$

Equation 5 has a wave solution. For instance, for small amplitude movements in a fluid with stable density stratification, this solution can be in the following form:

$$
w=\hat{w}(z) e^{i(k x+l y-\omega t)}
$$

Where $\hat{w}(z)$ is vertical structure of amplitude of vertical movements that can include multiple modes of Wn $(\mathrm{n}=0,1,2,3,4, \ldots)$. These modes are orthogonal functions and are known as normal modes. $\mathrm{K}$ and $\mathrm{L}$ are horizontal components of vector of turbulence wave number and $\omega$ is turbulence frequency and exponential part of this term indicates time horizontal structure of the turbulence. Amplitude of the vertical movement of particles of the fluid proportional to $w_{n}$ is $\mathrm{h}_{\mathrm{n}}$ and in case where Boussinesq approximation is applicable, by replacing equation 6 into equation 5 , it can be indicated that vertical structure of normal modes is as the following relation [10]:

$$
\frac{d^{2} \hat{w}}{d z^{2}}+\frac{\left(N^{2}-\omega^{2}\right)\left(k^{2}+l^{2}\right)}{\omega^{2}} \hat{w}=0
$$

So that for fixed and positive values of $\mathrm{N}$ has trigonometric solution as follows:

Also we have:

$$
\hat{w}=\sin \left(\frac{\left(N^{2}-\omega^{2}\right)\left(k^{2}+l^{2}\right)}{\omega^{2}}(z+H)\right.
$$

$$
\frac{d^{2} h_{n}}{d z^{2}}+\left(\frac{N}{C_{n}}\right)^{2} h_{n}=0
$$

Where $\mathrm{C}_{\mathrm{n}}$ is phase velocity of mode "n" and we have $C_{n}^{2}=g H_{e}$ in which $H_{e}$ is the equivalent height [10].

For $\mathrm{n}=0$, movement mode is the same barotropic mode which its phase velocity is $\sqrt{g H}$ and $\mathrm{H}$ is height of the stratum. For $\mathrm{n}>0$, modes are related to baroclinic movements and $1 / C_{n}$ is the especial value according to 
especial functions of $h_{n}(z)$. For a medium with fixed $\mathrm{N}$, solution of equation 8 with boundary conditions $h_{n}=0$ in $z=0,-H$ is as follows:

$$
\frac{d^{2} h_{n}}{d z^{2}}+\left(\frac{N}{C_{n}}\right)^{2} h_{n}=0
$$

Boundary conditions of $h_{n}=0$ in surface of the fluid stratum indicates rigid lid approximation. Structure of these functions for various modes is in a way that for $n=1$, the function has one peak and for $n=2$, the function has two peaks, and etc. By having $w_{n}$ in accordance with $h_{n}$, horizontal velocities of $\mathrm{u}_{\mathrm{n}}$ can also be obtained by using conservation equation [6]. Of course, in the model proposed by Wong et al., effect of molecular cohesion has also been considered which indicates that vertical structure of normal modes have attenuation. This effect (attenuation) can also be observed in field and experimental observations (figure 6) [11].

Due to existence of density difference between two points of the same height from two basins of the Caspian Sea and also density difference between two points in the same distance from coast and of different heights, value of $\mathrm{N}$ is variable. Therefore, there is no analytic solution for equation 7 and numerical method should be applied. For this purpose, first the two basins in the Caspian Sea are networked and then the equation governing internal waves on points of the network are solved. Equation of internal waves will be written in directions of $\mathrm{x}$ (along north-south direction of the Caspian Sea) and z (along vertical direction from surface to bottom of the sea) in 2D coordinate system according to equation 5 by considering assumptions of incompressibility and non-cohesiveness of the fluid and using Boussinesq approximation as follows [10]:

$$
\frac{\partial^{2}}{\partial t^{2}}\left[\frac{\partial^{2}}{\partial x^{2}}+\frac{\partial^{2}}{\partial z^{2}}\right] w+N^{2}\left(\frac{\partial^{2}}{\partial x^{2}}\right) w=0
$$

After netting the basin, origin of the coordinate is assumed on the southern coast of the Caspian Sea (Nowshahar City), then general answer of the equation is defined as follows [7]:

$$
w(x, z, t)=\sum_{j}\left\{a_{j} W_{j}(z) \cdot \cos \left(k x-\omega_{j} t\right)\right\}
$$

Considering boundary conditions for all "J", the following relation exists:

$$
W_{j}(0)=W_{j}(H)=0
$$

By replacing equation 11 in equation 10, the following equation is obtained:

$$
\begin{gathered}
\sum_{j}\left\{\cos \left(k x-\omega_{j} t\right) a_{j}\left(W_{j}^{\prime \prime} \omega_{j}^{2}+W_{j} k^{2}\left(N^{2}-\omega^{2} j\right)\right\}=0\right. \\
\Rightarrow W_{j}^{\prime \prime} \omega_{j}^{2}+W_{j} k^{2}\left(N^{2}-\omega_{j}^{2}\right)=0
\end{gathered}
$$

Considering conservation equation of $\frac{\partial u}{\partial x}+\frac{\partial w}{\partial z}=0$, we have:

$$
\begin{gathered}
u(x, z, t)=-\Sigma_{j}\left\{a_{j} W_{j}^{\prime}(z)\left(\frac{-1}{k}\right) \sin \left(k x-\omega_{j} t\right)\right\} \\
\Rightarrow U_{j}=\frac{-1}{k} W_{j}^{\prime}
\end{gathered}
$$

First, $\mathrm{Wj}$, vertical velocity of internal waves, is obtained in the $\mathrm{J}$ defined in equation 13 , then $\mathrm{Uj}$ which is horizontal velocity of internal waves in the $\mathrm{J}$ defined in equation 15 is obtained.

For calculating $\mathrm{Wj}$, equation 13 is solved by using finite difference method which means the term $\frac{\partial^{2} w}{\partial z^{2}} \quad$ to the defined and limited value. For this purpose, backward difference method is used which means the derivative is 
situated as function in various points, in fact derivative is made separated by Taylor Series:

$$
\left.\frac{d^{2} W}{d z^{2}}\right|_{j, i-1}=\frac{W_{j, i}-2 W_{j,(i-1)}+W_{j,(i-2)}}{\Delta z^{2}}
$$

By replacing equation 16 in equation 13, the following relation is obtained:

$$
\frac{W_{j, i}-2 W_{j,(i-1)}+W_{j,(i-2)}}{\Delta z^{2}}+k^{2}\left(\frac{N_{j,(i-1)}^{2}}{\omega_{j, i}^{2}}-1\right) W_{j,(i-1)}=0
$$

$\mathrm{K}$ is wavenumber and $\mathrm{L}$ is wavelength. If wavelength is assumed to be one eighth of length of the region, by using relation of the wavenumber;

$$
k=\frac{2 \pi}{L}
$$

wavenumber value for calculations obtained as equal to $2 \pi \times 10^{-5} \mathrm{~m}^{-1}$.

$\mathrm{N}$ is the buoyancy frequency, $\omega$ is wave frequency, $\mathrm{C}$ is wave propagation velocity, $\mathrm{g}^{\prime}$ is the reduced gravity intensity, and $\mathrm{h}$ is the height of water from sea level, then the following relations are obtained:

$$
\begin{gathered}
N^{2}=\frac{\Delta \rho}{\Delta z} \cdot \frac{g}{\rho} \\
N_{j,(i-1)}^{2}=\frac{\rho_{j,(i-1)}-\rho_{j, i}}{\rho_{j,(i-1)}+\rho_{j, i}} \frac{2 g}{\Delta z} \\
\omega=k c \\
\omega_{j(i-1)}=k\left(g^{\prime} h\right)^{1 / 2} \\
\omega_{j,(i-1)}^{2}=k^{2} \frac{\rho_{j,(i-1)}-\rho_{j, i}}{\rho_{j,(i-1)}+\rho_{j, i}} 2 g h \\
\frac{N^{2}(j, i-1)}{\omega^{2}(j, i-1)}=\frac{1}{k^{2} \Delta z h}
\end{gathered}
$$

It is observed that for solving these equations, first $\mathrm{j}$ and $\mathrm{i}$ should be defined in the region being studied. Hence, networking method should be used. $\mathrm{W}_{\mathrm{j}, \mathrm{i}}$ indicates vertical velocity in specific $\mathrm{i}$ and $\mathrm{j}$ which are situated in a specific point, $W_{j, i-1}$ indicates vertical velocity in a point with distance $\Delta x$ from the coast and with height difference equal to $\Delta z$ before the point $(\mathrm{i}, \mathrm{j})$, and $W_{j,(i-2)}$ indicates vertical velocity in a point with $\Delta x$ distance from the coast and height difference equal to $2 \Delta z$ before the point $(\mathrm{i}, \mathrm{j})$.

\subsection{Networking Method}

In order to calculate $\mathrm{W}$, the region of the study should be networked in terms of $\mathrm{i}$ and $\mathrm{j}$.For this purpose, according to figure 2, we divide $\mathrm{X}$ axis into 12 equal divisions with $70 \mathrm{~km}$ distance from each other, indicate $\mathrm{j}$ on the $X$ axis so that we would have points from 1 to 13 and we divide $Z$ axis into 40 equal divisions with $20 \mathrm{~km}$ distance from each other, indicate $i$ on $Z$ axis so that we would have $i$ from 1 to 40 . In this case, $j=1$ and $i=1$ are related to origin of $2 \mathrm{D}$ coordinate system, so for $\mathrm{i}$ and $\mathrm{j}$ we will have:

$$
\mathrm{j}=1,2,3,4, \ldots, 13
$$




$$
\mathrm{i}=1,2,3,4, \ldots, 40
$$

Therefore, distance between two successive $\mathrm{j}$ parameter is $70 \mathrm{~km}$ and the distance between two successive $\mathrm{i}$ parameters is $20 \mathrm{~km}$. Distance between two successive i parameters is equal to $\Delta z$ between the two pointsand $\mathrm{h}$ value which is height from sea level is equal to $(i-1) \Delta z$ :

$$
h=(i-1) \Delta z=20(i-1)
$$

\subsection{Calculation of Vertical Velocity}

According to the networking method, first we compare various points of the network with first tour research stations of the International Atomic Energy Agency:

$\mathrm{j}=1$ is located in margin of south coast of the Caspian Sea and border of the south basin is northern coast of Iran, in this point velocity is equal to zero, which means:

$$
W(1, i)=0
$$

$\mathrm{j}=2$ is located between the south coast of Caspian Sea and station 1 of first marine tour of International Atomic Energy Agency. For calculating data related to this point, interpolation method is used and the data related to $\mathrm{j}=2$ which extends in $70 \mathrm{~km}$ distance from coast of Caspian Sea is obtained from surface to bottom of the sea.

$\mathrm{j}=3$ is almost located on station 1 of first marine tour of International Atomic Energy Agency. The data of CTD of the station can be used for $\mathrm{j}=3$ which extends in $140 \mathrm{~km}$ distance from coast of Caspian Sea from surface to bottom of the sea.

Accordingly, the point $\mathrm{j}=4$ is almost located on station 2 , the point $\mathrm{j}=5$ is almost located on station 3 , the point $\mathrm{j}=6$ is almost located on station 4 , the point $\mathrm{j}=7$ is almost located on station 5 , the point $\mathrm{j}=8$ is almost located on station 6 , the point $\mathrm{j}=9$ is almost located on station 7 , the point $\mathrm{j}=10$ is almost located on station 8 , the point $\mathrm{j}=11$ is almost located on station 9 , and the point $\mathrm{j}=13$ is almost located on station 11 , so that we can apply the measurements related to marine first tour stations as the mentioned order for points with specific $J$. But $\mathrm{j}=12$ is almost located on station 11 of first marine tour of International Atomic Energy Agency so that was deleted because of low depth of measurements of first tour of International Atomic Energy Agency, so the required data for $\mathrm{j}=12$ which have been obtained by interpolation are used.

Therefore, points $\mathrm{j}=12$ and $\mathrm{j}=13$ are located in northern part of the Caspian Sea and these regions have low depth, then because of low depth we can assume the velocity in point 13 as zero:

$$
W(13, i)=0
$$

So for solving equation 13 we can apply the following hypothesis as one of the boundary conditions: $W(1, i)=W(13, i)=0$

Also vertical velocity in bottom of the sea is equal to zero. Therefore, for each specific $j$, considering topography of bottom of the Caspian Sea, when reaching bottom of the sea, vertical velocity of the said point becomes zero. Equation 13 after replacement and simplification is written as below:

$$
W_{j, i}+\left(-2+\frac{1}{i-1}-16 \pi^{2} \times 10^{-8}\right) W_{j,(i-1)}+W_{j,(i-2)}=0
$$

We solve equation 23 by using MATLAB.6 software, we obtain vertical velocity in each node, meaning that we obtain $W_{j}$ in certain $\mathrm{j}$ with different i parameters and hence, first we obtain $W_{j}=2$ in $\mathrm{i}=1,2, \ldots$. We follow the same process for all different $\mathrm{j}$ parameters so that $W_{j}$ profiles are respectively depicted. Profiles of vertical velocity in stations 4,5 , and 6 are observed in figure 4 . In fact these profiles indicate vertical modes of internal waves.

\subsection{Calculation of Horizontal Velocity}

After calculating $W_{j, i}$ we find values of $\mathrm{U}_{\mathrm{j}, \mathrm{i}}$ and since $\mathrm{U}_{\mathrm{j}, \mathrm{i}}$ indicates horizontal velocity in point $(\mathrm{i}, \mathrm{j})$, for calculating $\mathrm{U}_{\mathrm{j}, \mathrm{i}} \mathrm{We}$ use the following relations:

$$
\begin{gathered}
U_{j, i}=\frac{-1}{k} W_{j, i}^{\prime} \\
U_{j, i}=\frac{-1}{k} \frac{\partial W_{j, i}^{\prime}}{\partial z}
\end{gathered}
$$




$$
\frac{\partial W_{j, i}^{\prime}}{\partial z}=-k U_{j, i}
$$

Hence, by applying finite difference method through backward Euler method, equation 24 is solved:

$$
\begin{gathered}
\frac{W_{j, i}-W_{j, i-1}}{\Delta z}=-k U_{j, i} \\
U_{j, i}=\frac{-\left(W_{j, i}-W_{j, i-1}\right)}{20 k}
\end{gathered}
$$

Therefore, by having values of $W_{j, i}$ and $W_{j, i-1}$, we can obtain $U_{j, i}$ in each point. Like calculation of $W_{j, i}$, we also find $U_{j, i}$ in the certain $\mathrm{j}$ for i parameters existed, then $\mathrm{U}_{\mathrm{j}}$ profile like $W_{j}$ profile is drawn in various $\mathrm{j}$ parameters. Profiles of horizontal velocity in stations 4, 5, and 6 are indicated in figure 5. In fact these profiles indicate vertical and horizontal modes of internal waves.

\subsection{Density Calculation Method}

After calculating $\mathrm{U}$ and $\mathrm{W}$, density value will be considered. According to mass conservation equation we have:

$$
\frac{\partial \rho}{\partial t}+u \frac{\partial \rho}{\partial x}+w \frac{\partial \rho}{\partial z}=0
$$

We use finite difference method by using backward Euler method for simplifying equation 26, so that we have:

$$
\begin{aligned}
& \left.\frac{\partial \rho}{\partial x}\right|_{j, i}=\frac{\rho_{j, i}-\rho_{(j-1), i}}{\Delta x} \\
& \left.\frac{\partial \rho}{\partial z}\right|_{j, i}=\frac{\rho_{j, i}-\rho_{j,(i-1)}}{\Delta z}
\end{aligned}
$$

We replace equations 27 and 28 in equation 26 and obtain equation 29:

$$
\begin{gathered}
\frac{\partial \rho}{\partial t}=-U_{j, i} \frac{\rho_{j, i}-\rho_{(j-1), i}}{\Delta x}-W_{j, i} \frac{\rho_{j, i}-\rho_{j,(i-1)}}{\Delta z} \\
\Delta x=7 \times 10^{4} \mathrm{~m} \\
\Delta z=20 \mathrm{~m}
\end{gathered}
$$

Hence, equation 29 is solved and value of $\frac{\partial \rho}{\partial t}$ for certain $\mathrm{i}$ and $\mathrm{j}$ can be obtained.

Also it can be noted that:

$$
\begin{gathered}
\frac{\partial \rho}{\partial t} \approx \frac{\Delta \rho}{\Delta t} \\
\Delta \rho \approx\left(\frac{\partial \rho}{\partial t}\right) \times \Delta t
\end{gathered}
$$

when we have $\Delta t$ assumed as regulation time or collapse time of mixed water column after mixing. Considering the distance between the first two points symmetry to each other in two sides of the crest between south and middle basins which have noticeable density difference, we obtain value of $\mathrm{L}$ from equation 31 , then by considering properties related to these points which one belongs to $j=6$ and the other one belongs to $j=8(j=7$ is above the situated obstacle), we can obtain $\Delta t$ which is collapse time [12].

$$
\Delta t=\frac{L}{\left(g^{\prime} h\right)^{1 / 2}}
$$

Value of $\Delta t$ is obtained almost as equal to $29300 \mathrm{sec}$, value of $\Delta \rho$ is obtained in each station for less values 
than this time as $22800 \mathrm{sec}$, and more values of time as $45600 \mathrm{sec}$ and $500000 \mathrm{sec}$ and $1000000 \mathrm{sec}$. Also we have:

That also can be written as follows:

$$
\rho=\rho_{0}+\rho^{\prime}
$$

$$
\rho=\rho_{0}+\Delta \rho
$$

Therefore, by having $\Delta \rho$ and $\rho_{0}$ we obtain value of $\rho$ for the said times so that we can compare density profiles obtained with the primary density profile (drawn by data resulted from fist research tour measurements of UNESCO). According to the comparison it can be observed that the calculated density profile has an appropriate coordination with the primary density profile (figures 6). Meaning that internal waves are effective in structure of strata of waters of south and middle basis of Caspian Sea.

\section{Effect of Internal Waves on Energy Transfer}

According to the observations from field studies (drawing density ratio profile), it was found that dual distribution convection is not often created in Caspian Sea and it doesn't seems that this convection has a main role in stratified structure in the Caspian Sea, but also waves have a main role in these waters.

Field studies confirm existence of surface flows from north to south and also creation of flow from surface water of the middle basin and upwelling of this flow from depth. Transfer of this flow occurs together with water stratification and creation of internal waves. Also analytic studies confirm existence of such waves and water stratification and figure 4 indicates existence of vertical modes of internal waves in Caspian Sea. Figure 6 indicates appropriate consistency existing between calculation results and results obtained from first tour research measurements. This fact implies existence of internal waves which cause creation of stratified structure. Generally, in the Caspian Sea, normal modes of internal waves are produced with long wavelength by entrance of rivers in an environment with stratified layers, and finally result in complete stratification of Caspian Sea, so that within long period of time, the flow transfers from one stratum to another, movement of this flow causes excitation of the internal waves which propagate energy towards vertical direction. Internal waves, in environments with stable density stratification like Caspian Sea waters, can transfer energy. Meaning that this flow, together with changes in velocity due to passage of various strata of water with different densities, reaches water surface and then the phenomenon of water rotation on surface of the sea can be observed. Sometimes when internal waves break, turbulence caused by this event, creates stratified structure [10]. The main reason of creation of exchange flow between the two basins of the Caspian Sea is horizontal gradient of density, that in this phenomenon, internal waves are created and have effect on this exchange, and sign of existence of such internal waves is stratified structure observed. The Stratified structure in Caspian Sea mainly exists in the part under the mixed stratum. Thickness of the strata in Caspian Sea waters is almost $10 \mathrm{~m}$ to $20 \mathrm{~m}$ and the number of them varies from 3 to 7 .

Existence of stratified structure also has effect on thermal distribution coefficient and cause transfer of heat in Caspian Sea waters and is also effective in extent of exchange of waters. Also existence of various water strata with different densities is effective in propagation of sound waves which is considered as mechanical waves, so that the more an stratum is denser, the more velocity of sound wave increases in that stratum. Hence, in various water strata, sound wave is also different and at the time of passage of sound from one stratum to another, failure phenomenon for sound waves occurs.

For converting kinematic energy of internal waves created along vertical direction inside Caspian Sea waters to the electrical energy, buoyancy systems which function with fluctuations of internal waves for driving hydraulic pumps, are used. This system is installed on a buoyant rod in the sea and is fixed on a device in bottom of the sea and a series of buoyant devices attached to it or restrained by it fluctuate with that wave. This movement strikes electric generator and creates electricity and electric energy produced is transferred by electricity cable under the sea to the coast, and for changing kinematic energy of internal waves created along vertical direction of Caspian Sea waters to electric energy, some devices which work with water fluctuation are used, so that by wave motion of water, and fluctuation of water, water column is filled and emptied. In this process, water is entered the compressed column and creates energy by working, then this energy is taken under control and transferred to the coast by electricity cable.

\section{Conclusion}

Considering numerical calculations, value of vertical velocity related to movement of internal waves is obtained as $10^{-6}$ to $10^{-3} \mathrm{~m} / \mathrm{s}$, meaning that vertical movements of internal waves occurs slowly. The calculated horizontal 
velocity is also obtained as $10^{-3}$ to $10^{-1} \mathrm{~m} / \mathrm{s}$. Profile of vertical and horizontal velocities obtained from solving equations and also profile of density is drawn after pass of four different time integration steps. These profiles indicate that due to passage of gravitational flow between the two basins, density in various points of the two basins change, and since south and middle basins of Caspian Sea are related to each other through a mound (Abshouran point), in the conducted studies it is observed that flow of the middle basin moves towards the south basin and overflows from top of the mound between the two basins, then from bottom of the mound, the flow returns towards the middle basin. And this fact is consistent with measurements conducted by UNESCO (1995).

Since for creation of dual distribution convection density ratio should be almost equal to 1 , this phenomenon does not often occur in this sea (figure 3), hence we cannot attribute the observed strata to this phenomenon. But the modal structure created from internal waves on the mound causes creation of shear strata observed. The created strata, in addition to distributing organic substance and also oxygen existing in Caspian Sea waters, causes energy transfer that by using energy convertor of waves in this place, electric energy is produced.

\section{References}

Bains, W. D., \& Turner, I. S. (1969). Turbulent buoyant Convection from a source in a confined region. J. Fluid Mech., 34, 51-80.

Bidokhti, A. A., \& Griffiths, R. W. (2001). Internal waves as an additional mechanism for layering in the outflows from semi enclosed seas.14th Australasian Fluid Mechanics Conference.

Bidokhti, A. A., \& Noroozi, M. (2004). A Physical Model for the layered structure of a density driven flow over a slope. Tenth Asian Congress of fluid Mechanics, Seri Lanka.

Bidokhti, A. A., \& Shekarbaghani, A. (2011). The layered structure in exchange flows between two basins (Middle and Southern basins of the Caspian Sea). Int. J. Mar. Sci. Eng., 1(1), 13-22.

Boehrer, B. (2000). Modal response of a deep stratified Lake: Western lake Constance. J. Geophys. Res., 105, 2383- 2384 .

Fedrov, K. N. (2013). The Physical Nature and Structure of Oceanic Fronts. http://dx.doi.org/10.1029/LN019

Gill, A. E. (1982). Atmoshperic and ocean dynamics. Academic press N.

Griffiths, R. E. (2008). Interleaving intrusions produced by internal waves: a laboratory experiment. J. Fluid Mech., 602, 219-239.

Hogg, A., Mc, C., Winters, K. B., \& Ivey, G. N. (2001). Linear internal Waves and the control of stratified exchange flows. J. Fluid Mech., 447, 357-375.

Ruddick, B. R. (1992). Intrusive mixing in Mediterranean salt lens-intrusion slopes and dynamical mechanisms. J. Phys. Oceanogr, 22, 1274-1285.

UNESCO, IHP-IOC-IAEA. (1995).Workshop on sea level rise and multidisciplinary studies of environmental processes in the Caspian region 9-12 May. Paris, Farance IOC workshop, 108.

Wong, B. D., Griffiths, R. W., \& Hughes, G. O. (2001). Shear Layers driven by turbulent plumes. J. Fluid Mech, 434, 209-244.

\section{Appendix A}






Figure A1. Map of the Caspian Sea and the stations of measurement

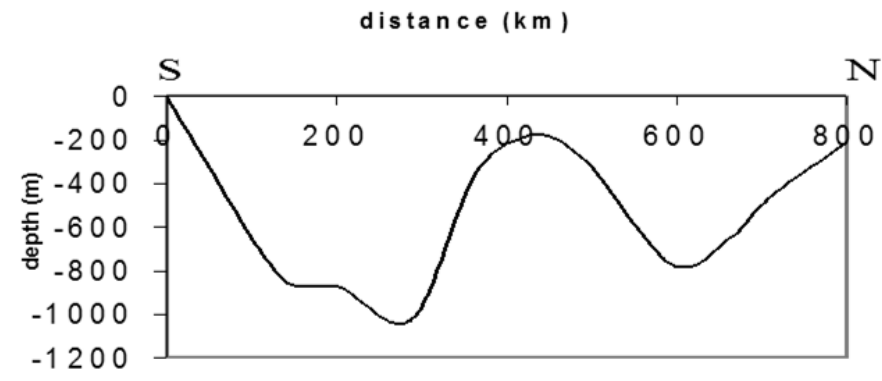

Figure A2. Bottom topography of the Caspian Sea is indicated by distance from southern shore in southern -northern direction 
$\$ 4$

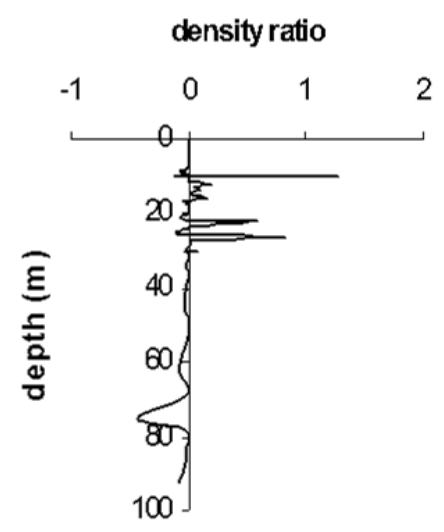

s5

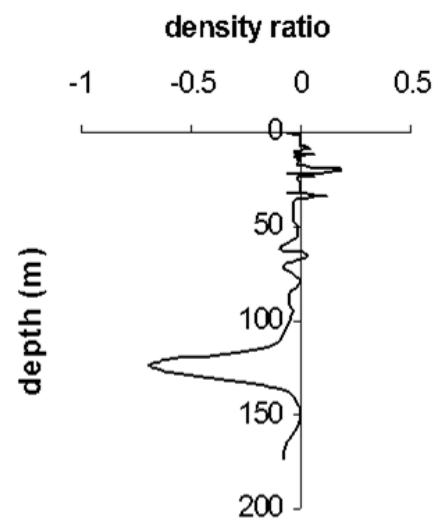

s6



Figure A3. Vertical profile of density ration in stations 4, 5, and 6

$W(\mathrm{~m} / \mathrm{s}) \quad(\mathrm{x}=350 \mathrm{~km})$

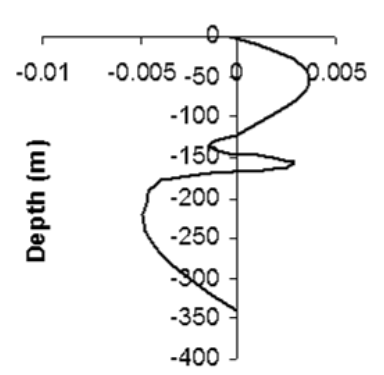

s4 $\mathrm{j}=6$
$W(\mathrm{mis}) \quad(x=420 \mathrm{~km})$



s5 $j=7$
$W(\mathrm{~m} / \mathrm{s}) \quad(\mathrm{x}=490 \mathrm{~km})$

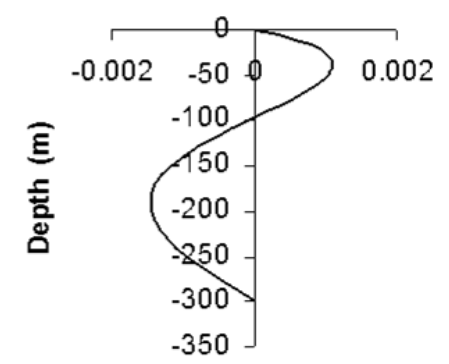

s6 $\quad j=8$

Figure A4. Profiles of vertical velocity calculated by numerical method in stations 4, 5, and 6 (x distances are from Caspian Sea south coast)

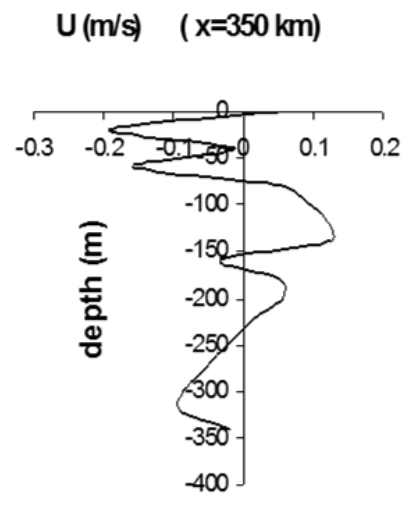

$\mathrm{s} 4 \mathrm{j}=6$

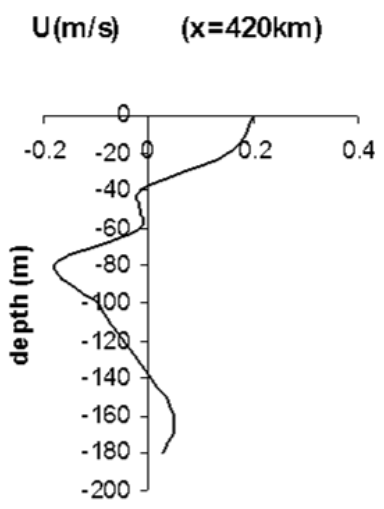

s5 $\mathbf{j}=7$

\section{$\mathrm{u}(\mathrm{m} / \mathrm{s}) \quad(\mathrm{x}=490 \mathrm{~km})$}



$\mathrm{s} 6 \mathrm{j}=8$

Figure A5. Profiles of horizontal velocity calculated by numerical method in stations 4, 5, and6 (x distances are from Caspian Sea south coast) 




s4

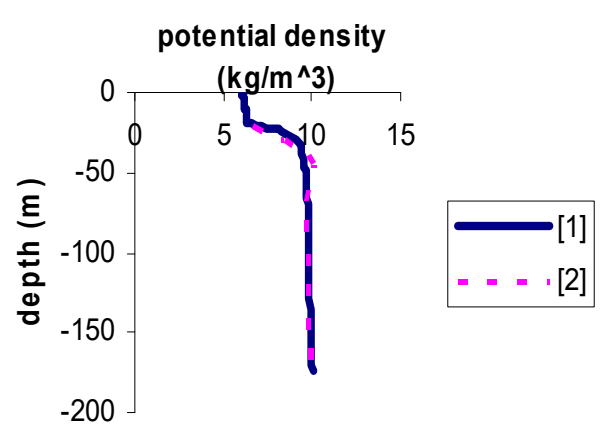

s5


s6

s7

Figure A6. Comparison between the primary potential density profile obtained from first research tour measurements of UNESCO [1] and potential density profile calculated by numerical method [2] in stations 4, 5, 6 , and 7
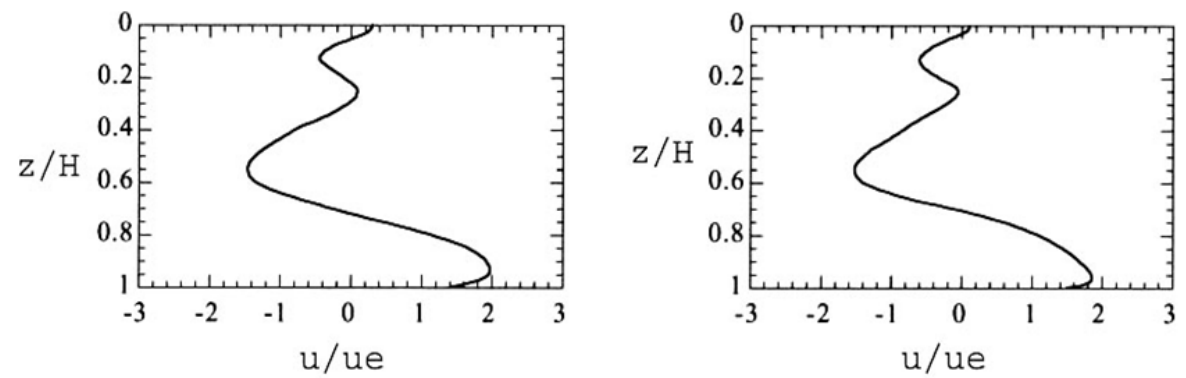

Figure A7. Horizontal velocity made dimensionless by internal velocity of mixing obtained in two successive times created in the same stratified structure by a plume in a closed environment with density stratification

\section{Copyrights}

Copyright for this article is retained by the author(s), with first publication rights granted to the journal.

This is an open-access article distributed under the terms and conditions of the Creative Commons Attribution license (http://creativecommons.org/licenses/by/3.0/). 